\title{
Det ekstremt for tidlig fødte barnet; hvordan går det?
}

\author{
Trond Markestad \\ Professor emeritus, Universitetet i Bergen \\ trond.markestad@uib.no
}

\begin{abstract}
This is an open access article distributed under the Creative Commons Attribution Licence, which permits unrestricted use, distribution, and reproduction
\end{abstract} in any medium, provided the original work is properly cited.

Sønn av president John F. Kennedy og kona Jacqueline, Patrick, ble født $51 / 2$ uke for tidlig i 1963 og veide 2110 gram. Han døde etter 2 døgn av neonatalt åndenødssyndrom (respiratory distress syndom - RDS) som skyldes mangel på surfaktant. Det var det vanlige utfallet av betydelig prematuritet den gangen. Patricks død ga støtet til økt forskning i nyfødtmedisin. I 1964 viste Paul R. Swyer i Toronto at for tidlig fødte barn med umodne lunger kunne overleve med respiratorbehandling ${ }^{1}$, og respiratorbehandling ble snart rutine. De neste store fremskrittene var å gi glukokortikoid til mor før fødsel for å fremme fosterets surfaktantsyntese $^{2}$ (rutine fra ca. 1980) og å sprøyte farmasøytisk fremstilt surfaktant ned i lungene (fra begynnelsen av 1990-tallet) ${ }^{3}$. Sammen med bedre teknologi for assistert ventilasjon og overvåkning av vitale funksjoner, samt økt kunnskap og kompetanse, har dette ført til at få av barna dør av lungesykdom i dag.

Selv om risikoen for død og alvorlige funksjonsnedsettelser øker med grad av prematuritet ${ }^{4}$, er det i dag størst bekymring knyttet til fremtidig helse og funksjonsnivå hos barn som overlever ekstrem prematuritet, dvs. fødsel før 28 ukers svangerskap. Det gjelder ca. $0,5 \%$ av alle fødsler i Norge, ca. 300 barn per år ${ }^{5}$. I dag er det mulig å redde noen barn som fødes i uke 22, men hva som bør være en nedre grense for å tilby livreddende behandling, diskuteres kontinuerlig. I Sverige er det blitt vanlig å behandle fra 22 svangerskapsuker ${ }^{6,7}$ mens Frankrike i praksis ikke gir livreddende behandling ved 23 uker og i langt mindre grad enn hos oss ved 24 uker $^{8}$. I Norge diskuteres det om det er etisk akseptabelt å avstå fra å gi livreddende behandling ved fødsel før 24 svangerskapsuker, og om hvilke skader og sykdom som kan være grunnlag for å avslutte livsforlengende behandling ${ }^{9}$. En fersk spørreundersøkelse viser at alle føde- og barneavdelingene i Norge i praksis gir livreddende behandling ved fødsel i uke 24 uten vanligvis å gå inn på en diskusjon om dette med foreldrene, og også i uke 23 dersom foreldrene ønsker eller aksepterer $\operatorname{det}^{10}$. Noen få barn har de siste årene også overlevd etter fødsel i uke 22.

Nyfødtmedisinen må nok alltid leve i en gråsone for når det er rimelig å tilby livreddende behandling og for hva foreldrene skal kunne kreve, både med hensyn til å avstå fra og forlange aktiv behandling. Forskningsbasert kunnskap om prognose med tanke på overlevelse og risiko for funksjonsnedsettelser, belastning for barnet og familien og kostnad for samfunnet, er grunnleggende for en fruktbar diskusjon om grenser for å starte livreddende behandling, sammen med vekting av etiske prinsipper om retten til liv.

\section{FORSKNINGSBASERT KUNNSKAP}

Forskningen er omfattende, men jeg vil i hovedsak vise til erfaringene fra en fersk metaanalyse fra Nasjonalt kunnskapssenter for helsetjenesten ${ }^{10}$, den norske studien Prosjekt Ekstrem Prematuritet (PEP) som omfatter alle barn født før 28 svangerskapsuker eller med en fødselsvekt under 1000 gram i Norge i 1999 og $2000^{11,12}$, den svenske EXPRESS-studien som omfatter alle barn med svangerskapsalder under 27 uker født $i$ Sverige i $2004-2007^{6,7}$, og de to engelske EPICurestudiene som omfatter alle barn med svangerskapsalder under 26 uker i Storbritannia i 1995 (EPICure 1) og 2006 (EPICure2) ${ }^{13,14}$.

\section{OVERLEVELSE}

For de laveste svangerskapsaldrene avhenger overlevelsen i stor grad av holdningen til å tilby livsforlengende behandling. Ved fødsel i 22 og 23 ukers svangerskapsalder er det kanskje mulig å oppnå en overlevelse på henholdsvis en tredel og nær halvparten dersom alle blir forsøkt resuscitert og eventuelt forløses med keisersnitt ved truende fosterdød (Tabell 1), mens alle vil dø uten slike tiltak. Det ser heller ikke ut til at andelen med alvorlige funksjonsnedsettelser øker med økende overlevelse som følge av en mer proaktiv holdning til å gi livreddende behandling ${ }^{6}$. I Norge var overlevelsen den samme for svangerskapsaldrene 2326 uker for barn født i 1999-2000 og 2013-2014 $(\text { Tabell } 2)^{15}$. Det kan bety at vi nærmer oss grensen for hva som er mulig å oppnå på befolkningsnivå i dag, men også at vi fortsatt er tilbakeholdende med aktiv behandling ved grensen for levedyktighet. I den siste perioden ble imidlertid 5 barn født i uke 22 behandlet, og 3 av dem overlevde ${ }^{15}$.

Tabell 1. Overlevelse (\%) for alle fødsler (inklusive dødfødte), for levende fødte og for barn innlagt $\mathrm{i}$ nyfødtintensivavdeling avhengig av svangerskapsalder. Metaanalyse av fødsler fra og med år $2000^{10}$.

\begin{tabular}{cccc}
\hline $\begin{array}{c}\text { Svangerskaps- } \\
\text { alder (uker) }\end{array}$ & $\begin{array}{c}\text { Alle } \\
\text { fødsler }\end{array}$ & $\begin{array}{c}\text { Levende } \\
\text { fødte }\end{array}$ & $\begin{array}{c}\text { Innlagt } \\
\text { intensiv }\end{array}$ \\
\hline 22 & $<5$ & 9 & 33 \\
23 & 10 & 27 & 48 \\
24 & 29 & 55 & 68 \\
25 & 52 & 73 & 78 \\
26 & 65 & 84 & 85 \\
27 & 80 & 90 & 92 \\
\hline
\end{tabular}


Tabell 2. Overlevelse (\%) i Norge avhengig av svangerskapsalder for barn født i 1999-2000 og 2013-14

\begin{tabular}{cccccccc}
\hline & \multicolumn{3}{c}{ Norge 1999-2000 } & \multicolumn{2}{c}{ Norge 2013-14 } \\
\cline { 2 - 7 } Svangerskapsalder (uker) & Alle fødsler & Levende fødte & Innlagt intensiv & Alle fødsler & Levende fødte Innlagt intensiv \\
\hline 22 & 0 & 0 & 0 & 5 & 18 & $60^{\text {a }}$ \\
23 & 16 & 26 & 39 & 17 & 29 & 35 \\
24 & 44 & 55 & 60 & 41 & 56 & 58 \\
25 & 66 & 77 & 80 & 59 & 84 & 86 \\
26 & 72 & 84 & 84 & 76 & 90 & 92 \\
27 & 82 & 92 & 93 & $?$ & $?$ & $?$ \\
\hline
\end{tabular}

a 3 av 5 barn gitt livreddende behandling overlevde.

Tabell 4. Forekomst (\%) og alvorlighetsgrader av nevrologiske og utviklingsmessige funksjonsnedsettelser ved 5-6 års alder i representative studier.

\begin{tabular}{lccccc}
\hline Studie & $\begin{array}{c}\text { Svangerskaps- } \\
\text { alder (uker) }\end{array}$ & Alvorlig $^{\mathrm{a}}$ & Moderat $^{\mathrm{b}}$ & Mild $^{\mathrm{c}}$ & Ingen $^{14}$ \\
\hline EPICure, Storbritania, 1995 & 23 & 25 & 38 & 25 & 12 \\
& 24 & 29 & 22 & 36 & 13 \\
& 25 & 18 & 22 & 35 & 25 \\
\hline EXPRESS, Sverige, 2004-07 $^{7}$ & 23 & 22 & 34 & 22 & 22 \\
& 24 & 19 & 21 & 34 & 26 \\
& 25 & 12 & 18 & 37 & 33 \\
\hline PEP, Norge, 1999-2000 & 26 & 9 & 16 & 25 & 50 \\
\hline
\end{tabular}

${ }^{a}$ Minst ett av følgende: cerebral parese (CP) uten evne til å bevege seg uten hjelpemidler, $\mathrm{IQ}<55$, blind eller døv; ${ }^{\mathrm{b}} \mathrm{CP}$ med evne til å bevege seg med hjelpemidler, IQ 55-70, alvorlig synssvekkelse eller avhengig av høreapparat; ${ }^{\circ} \mathrm{CP}$ uten behov for hjelpemidler, motoriske vansker uten CP, IQ 70-84, skjeling, annen synssvekkelse som krever briller eller nedsatt hørsel, men ikke høreapparat.

\section{KOMPLIKASJONER I NYFØDTPERIODEN}

De viktigste komplikasjonene i nyfødtperioden er hjerneblødninger (subependymal/intraventrikulær blødning-SEH), nekrose av hjernevev (periventrikulær leukomalaci - PVL), prematuritetsretinopati (ROP), nekrose av tarm (nekrotiserende enterokolitt - NEC) og bronkopulmonal dysplasi (BPD) definert som fortsatt behov for assistert ventilasjon eller oksygentilskudd fire uker før forventet termin. Forekomsten av alvorlige komplikasjoner var omtrent den samme for barna som ble født i Norge i 1999-2000 og 2013$2014^{15}$ (Tabell 3) og for barna født før 26 svangerskapsuker i EPICure 1- (født i 1995) og EPICure 2studien (født i 2006), men overlevelsen var noe høyere i $2006^{13}$.

\section{SENERE FUNKSJONSNIVÅ OG HELSE}

\section{Nevrologisk og kognitiv utvikling}

I den norske PEP-studien fikk $27 \%$ av barna som var født $\mathrm{i}$ uke 24, cerebral parese eller ble blinde eller døve (Figur 1). Forekomsten var lavere for 23 uker, sannsynligvis på grunn av en mer restriktiv holdning til livsforlengende behandling. Fra 26 uker var prognosen betraktelig bedre. Andre studier har vist at forekomsten av alvorlige nevrologiske, sansemessige og kognitive funksjonsnedsettelser øker markant med avtagende
Tabell 3. Andelen av overlevende barn (\%) som fikk alvorlige komplikasjoner i nyfødtperioden. Gjennomsnitt for barn født i Norge i 1999-2000 $0^{11,16}$ og 2013-2014 ${ }^{15}$.

\begin{tabular}{lcccc}
\hline Komplikasjon & $\begin{array}{c}23 \text { uker } \\
(\mathrm{n}=21)\end{array}$ & $\begin{array}{c}24 \text { uker } \\
(\mathrm{n}=70)\end{array}$ & $\begin{array}{c}25 \text { uker } \\
(\mathrm{n}=114)\end{array}$ & $\begin{array}{c}26 \text { uker } \\
(\mathrm{n}=157)\end{array}$ \\
\hline Alvorlig SEH/PVL $^{\mathrm{a}}$ & 5 & 20 & 14 & 10 \\
Alvorlig ROP $^{\mathrm{b}}$ & 33 & 26 & 14 & 3 \\
Alvorlig NEC $^{\mathrm{c}}$ & 10 & 7 & 4 & 3 \\
Alvorlig BPD $^{\mathrm{d}}$ & 57 & 53 & 29 & 27 \\
\hline
\end{tabular}

${ }^{\mathrm{a}} \mathrm{Grad}$ 3-4 subependymal hjerneblødning eller multicystisk periventriculær leukomalaci, ${ }^{\mathrm{b}}$ Stadium 3-5 eller laserbehandlet retinopati, ${ }^{\mathrm{c}}$ Stadium 2-3 eller kirurgisk behandlet nekrotiserende enterokolitt, ${ }^{\mathrm{d}}$ Bronkopulmonal dysplasi definert som behov for assistert ventilasjon eller minst $30 \%$ oksygen 4 uker før forventet termin.

svangerskapsalder. Forekomstene varierer også lite fra land til land og gjennom de siste 15-20 årene (Tabell 4). Barna i EPICure 1-studien, som var født i svangerskapsuke 23-25, ble fulgt til 11 års alder. Da fikk 81\% undervisning $\mathrm{i}$ spesialskole eller ekstra ressurser i vanlig skole på grunn av lav IQ eller spesifikke lærevansker. I kontrollgruppen fikk $11 \%$ ekstra ressurser ${ }^{17}$.

\section{Psykisk helse}

Barn med utviklingsmessige funksjonsnedsettelser har betydelig økt risiko for å utvikle atferdsproblemer, men selv blant de 11 år gamle barna i den norske PEPstudien som ikke hadde nevrosensoriske eller kogni- 
tive vansker, var det 3-4 ganger høyere forekomst av autistiske trekk, oppmerksomhetsvansker, angst- eller tvangssymptomer enn i en referansegruppe; $54 \%$ av de ekstremt premature barna hadde minst ett av disse trekkene mot $21 \%$ i referansegruppen ${ }^{18}$.

\section{Lungesykdom}

Kronisk lungesykdom er en fryktet følgetilstand etter ekstremt prematur fødsel. I PEP-studien økte forekomsten av lungesymptomer - hovedsakelig som astmatisk besvær - med grad av prematuritet. Plagene førte ofte til gjentatte innleggelser i sykehus de første årene, men plagene avtok fram mot 5 års alder ${ }^{19}$ (Figur 2). Senere i barneårene var det få av barna som hadde subjektive plager, men da de var 11 år hadde de økt bronkial obstruktivitet og reaktivitet ved formelle lungefunksjonsmålinger, dog bedre funksjon enn en tilsvarende gruppe født før surfaktant ble tilgjengelig ${ }^{20}$. Vi har funnet tilsvarende forskjeller mellom ekstremt premature og termin-fødte ved 25 års alder, men de fleste prematurt fødte hadde likevel verdier innenfor normalområdet ${ }^{21}$. Vi kjenner imidlertid ikke langtidsprognosen, f.eks. om de prematurt fødte vil ha økt risiko for tidlig utvikling av kronisk obstruktiv lungesykdom (KOLS).

\section{Livskvalitet}

Flere studier har vist at ungdommer født ekstremt prematurt rapporterer like god livskvalitet som ungdommer født til termin, men foreldrene vurderer deres livskvalitet som dårligere. Vi har fulgt en gruppe ekstremt for tidlig fødte fra 18 til 25 års alder. De rapporterte samme livskvalitet som kontrollgruppen da de var 18, men signifikant lavere kvalitet da de var 25 år ${ }^{22}$. En mulig tolkning er at voksenlivet byr på sosiale og yrkesmessige utfordringer som oppleves mer krevende for dem som er født for tidlig.

\section{KONKLUSJON}

Risikoen for å overleve med funksjonsnedsettelser øker markant med fallende svangerskapsalder under 26 uker. Det ser ikke ut til at andelen som overlever med funksjonsnedsettelser har avtatt signifikant de siste par

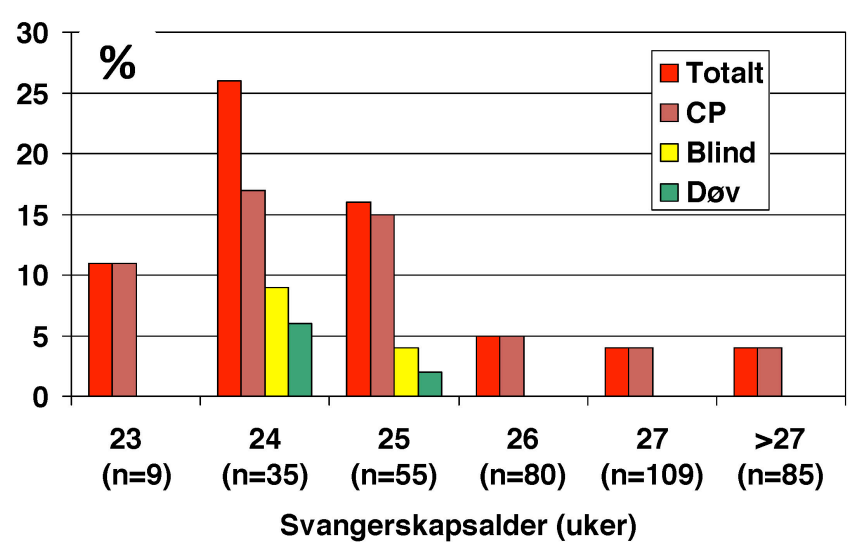

Figur 1. Forekomst av alvorlige nevrosensoriske funksjonsnedsettelser. Prosjekt ekstrem prematuritet (PEP) ${ }^{11}$.

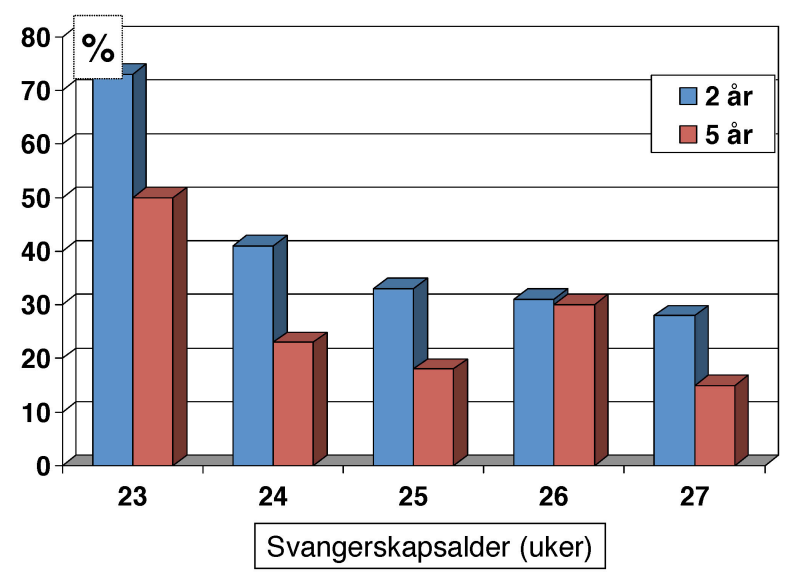

Figur 2. Forekomst av lungesymptomer ved 2 og 5 års alder. Prosjekt ekstrem prematuritet (PEP) ${ }^{11}$.

decenniene for disse barna, men litt økt overlevelse har ført til at antallet barn med og uten funksjonsnedsettelser har økt. Vi har ingen kunnskap om hva det betyr å være født ved grensen av levedyktighet for fysisk og psykisk helse, livskvalitet eller sosial og yrkesmessig fungering i godt voksen alder. Det er derfor viktig å følge kohorter av disse barna i mange tiår, både for å få kunnskap om hvilke behov de vil ha på lang sikt og for å identifisere tidlige risikofaktorer som kan peke mot mer optimal tidlig behandling og oppfølging.

\section{REFERANSER}

1. Delivoria-Papadopoulos M, Swyer PR. Assisted ventilation in hyaline membrane disease. Arch Dis Child 1964; 39: 481-4

2. Liggins GC, Howie RN. A controlled trial of antepartum glucocorticoid treatment for prevention of the respiratory distress syndrome in premature infants. Pediatrics 1972; 50: 515-25

3. Morley CJ. Surfactant treatment for premature babies - a review of clinical trials. Arch Dis Child 1991; 66: 445-50.

4. Helsedirektoratet (2007). IS-1419. Nasjonale faglige retningslinjer for oppfølging av for tidlig fødte barn (www.helsedirektoratet.no).

5. Medisinsk fødselsregister. https://www.fhi.no/hn/helseregistre-og-registre/mfr/ (05.09.2017).

6. Serenius F, Blennow M, Maršál K, Sjörs G, Källen K, EXPRESS Study Group. Intensity of perinatal care for extremely preterm infants: outcomes at 2.5 years. Pediatrics 2015; 135: e1163-72. 
7. Serenius F, Ewald U, Farooqi A, et al. for the Extremely Preterm Infants in Sweden Study Group. Neurodevelopmental outcomes among extremely preterm infants 6.5 years after active perinatal care in Sweden. JAMA Pediatr 2016; 170: 954-963.

8. Ancel PY, Goffinet F, EPIPAGE-2 Writing Group. Survival and morbidity of preterm children born at 22 through 34 weeks' gestation in France in 2011: results of the EPIPAGE-2 cohort study. JAMA Pediatr 2015; 169: $230-8$.

9. Ruud Hansen TW, Førde R. Premature og behandlingsgrenser. Tidsskr Nor Legeforen 2016; 136: 45-7.

10. Tinderholt Myrhaug H, Brurberg KG, Hov L, Håvelsrud K, Reinar LM. Prognose for og oppfølging av ekstremt premature barn. Systematisk oversikt. Folkehelseinstituttet, Avdeling for kunnskapsoppsummering, Kunnskapssenteret, 2017. https://www.fhi.no/globalassets/dokumenterfiler/rapporter/prognose-ekstremtpremature-barn-rapport-v2-2017.pdf.

11. Markestad T, Kaaresen PI, Rønnestad A, et al. for The Norwegian Extreme Prematurity Study Group. Early death, morbidity, and need of treatment among extremely premature infants. Pediatrics 2005; 115: 1289-98.

12. Leversen KT, Sommerfelt K, Rønnestad A, et al. Prediction of neurodevelopmental and sensory outcome at 5 years in Norwegian children born extremely preterm. Pediatrics 2011; 127: e630-8.

13. Johnson S, Marlow N. Charting the survival, health and development of extremely preterm infants: EPICure and beyond. Paediatr Child Health 2016; 26: 498-504.

14. Marlow N, Wolke D, Bracewell MA, Samara M, EPICure Study Group. Neurologic and developmental disability at six years of age after extremely preterm birth. $N$ Engl J Med 2005; 352: 9-19.

15. Stensvold HJ, Klingenberg C, Stoen R, et al., Norwegian Neonatal Network. Neonatal morbidity and 1-year survival of extremely preterm infants. Pediatrics 2017 ; 139. pii: e20161821.

16. Farstad T, Bratlid D, Medbø S, Markestad T. Norwegian Extreme Prematurity Study Group. Bronchopulmonary dysplasia - prevalence, severity and predictive factors in a national cohort of extremely premature infants. Acta Paediatr 2011; 100: 53-8.

17. Johnson S, Strauss V, Gilmore C, et al. Learning disabilities among extremely preterm children without neurosensory impairment: Comorbidity, neuropsychological profiles and scholastic outcomes. Early Hum Dev 2016; 103: 69-75.

18. Fevang SK, Hysing M, Markestad T, Sommerfelt K. Mental Health in children born extremely preterm without severe neurodevelopmental disabilities. Pediatrics 2016; 137 (4). pii: e20153002.

19. Skromme K, Leversen KT, Eide GE, Markestad T, Halvorsen T. Respiratory illness contributed significantly to morbidity in children born extremely premature or with extremely low birthweights in 1999-2000. Acta Paediatr 2015; 104: 1189-98.

20. Vollsæter M, Skromme K, Satrell E, et al. Children born preterm at the turn of the millennium had better lung function than children born similarly preterm in the early 1990s. PLoS One 2015; 10: e0144243.

21. Vollsæter M, Clemm HH, Satrell E, et al. Adult respiratory outcomes of extreme preterm birth. A regional cohort study. Ann Am Thorac Soc 2015; 12: 313-22.

22. Båtsvik B, Vederhus BJ, Halvorsen T, et al. Health-related quality of life may deteriorate from adolescence to young adulthood after extremely preterm birth. Acta Paediatr 2015; 104: 948-55. 